\title{
PATTERN OF PSYCHIATRIC REFERRAL IN A TERTIARY CARE HOSPITAL IN BANGLADESH
}

\author{
SULTANA ALGIN ${ }^{1}$, SUMAIYA NAWSHEEN AHMED², REDWANA HOSSAIN ${ }^{3}$
}

\begin{abstract}
Introduction: Consultation-liaison Psychiatry (CLP) is the study, practice and teaching of the relation between medical and psychiatric disorders.

Aim of the study: The aim of this study is to find out the referring department, reason for consultation, common psychiatric comorbidities and sociodemographic of the referred patients to psychiatry department from the other departments of Bangabandhu Sheikh Mujib Medical University of Dhaka.

Methodology: This cross-sectional study was carried out from May 2018 to February 2020. Patients referred from different inpatient departments every Thursday were taken as study population. Psychiatric diagnoses of the patients were assigned by the consultant psychiatrist as per DSM-5 criteria. Semi structured questionnaire was used to collect socio-demographic data.

Results: Among the referred patients ( $n=89)$ 56\% were female; 63\% were aged between 19-59 years; $65 \%$ were married; $58 \%$ were from urban background and $51 \%$ studied up to higher secondary. More than half of the patients were referred from different branches of Medicine (68\%). Referral from Internal Medicine was 14.6\%, Rheumatology 13.5\%, Neurology and Nephrology 10\% respectively. The rest were from the branches of pediatrics, surgery and gynecology. Most common psychiatric disorder was Major Depressive Disorder (37\%) followed by Obsessive-Compulsive Disorder (17\%) and Delirium (10.11\%). 15\% patient received no psychiatric diagnosis.
\end{abstract}

Conclusion: Psychiatric comorbidities in general medical illness are very common. CLP provides an opportunity to improve health outcomes for inpatients and reduce burden on the healthcare system.

Received: 11 May 2020

Accepted: 12 June 2020

DOI: https://doi.org/ 10.3329/bjm.v31i2.48536

\section{Introduction:}

Consultation-liaison Psychiatry (CLP) is the study, practice and teaching of the relation between medical and psychiatric disorders. ${ }^{1}$ CLP provides a huge scope for bridging the gap between medicine and psychiatry. Physical and psychiatric disorders often co-occur which complicates the course and prognosis of each disorder. Psychiatric consultation in general medical setting reduces the treatment cost, mortality, morbidity and treatment related stigma. ${ }^{2}$ Before establishment of psychiatric units in general medical hospital, psychiatric services were based on psychiatric hospitals only. The incorporation of psychiatric unit in general medical hospitals creates the opportunity for easy access to psychiatric services.
Bangladesh is a densely populated country with approximately 16 million people. Bangabandhu Sheikh Mujib Medical University (BSMMU) has been serving as one of the leading tertiary centers for people around the country since 1965 . BSMMU has been recognized as the center of excellence. The Department of Psychiatry of the university starts operating from 1975. Since inception, the department has been offering indoor, outdoor and referral services.

The prevalence of psychiatric disorder in Bangladesh is $16.8 \%$. Among them Depressive disorders (6.7\%), Anxiety disorders $(4.5 \%)$ and Somatic symptom and related Disorders $(2.1 \%)$ are high in frequency. But the treatment gap is $92.3 \%$ and most of the patients are treated by general physicians. ${ }^{3}$ Keeping in mind the scenario, it can

1. Associate Professor, Department of Psychiatry, Bangabandhu Sheikh Mujib Medical University;

2. Resident, Department of Psychiatry, Bangabandhu Sheikh Mujib Medical University;

3. Resident, Department of Psychiatry, Bangabandhu Sheikh Mujib Medical University;

Address of Correspondence: Dr. Sultana Algin, Associate Professor, Department of Psychiatry, Bangabandhu Sheikh Mujib Medical University; Mobile: 01552314981; email: algin28@gmail.com

Bangladesh J Medicine 2020; 31 : 76-80 
Pattern of psychiatric referral in a tertiary care hospital in Bangladesh

be assumed that psychiatric morbidities are high in people with medical disorders.

Researches in the psychiatric referral services has been increasing keeping in the mind the importance of this field. ${ }^{4}$ There are extensive studies in this field in western literature but researches conducted in Bangladesh are very scanty. The country has psychiatric units in almost all teaching medical hospitals but the pattern of psychiatric referrals from other departments, most commonly referring departments, common psychiatric co- morbidities in the referred population and their socio demographic is largely unexplored.

In the face of scanty studies in this regard, this study aims at exploring the sociodemographic, referring department and common psychiatric comorbidities of the referred patients to psychiatry department from the other departments of Bangabandhu Sheikh Mujib Medical University of Dhaka.

\section{Materials and Methods:}

This study was conducted in Department of Psychiatry, Bangabandhu Sheikh Mujib Medical University from May 2018 to April 2020. Sample was drawn from the referred patients from other clinical departments on selected day of the week (Thursday, as this is the scheduled referral day of the authors). This was a crosssectional study. The sociodemographic variables, psychiatric history, and mental state examination of the patient were made using a semi structured questionnaire. The complete assessment was done by trainee psychiatry resident, under the guidance of the consultant. Psychiatric diagnoses of the patients were assigned by the consultant psychiatrist as per Diagnostic and Statistical Manual- $5^{\text {th }}$ edition (DSM5) criteria.

\section{Results}

A total of 89 patients were referred for psychiatric consultation from various departments during the study period, out of which 39 (44\%) were males and $50(56 \%)$ were females. A majority of the patients belonged to the age group of $19-59$ years $(n=56,63 \%)$. The number of patients in the age groups of below 18 years and above 60 years were 19 (21\%) and 14 (16\%) respectively. Most of the patients studied up to higher secondary (51.69\%) and were housewives by occupation (33.7\%). Among the referred cases, 58.4\% patients came from urban background, and $65 \%$ were married [Table I].
Table I

Socio-demographic characteristics of referred patients

\begin{tabular}{|c|c|c|}
\hline Characteristics & Number & Percent \\
\hline \multicolumn{3}{|c|}{ Educational Status } \\
\hline Illiterate & 3 & 3.37 \\
\hline Primary & 20 & 22.47 \\
\hline Secondary & 46 & 51.69 \\
\hline Graduate & 16 & 17.98 \\
\hline Post Graduate & 4 & 4.49 \\
\hline \multicolumn{3}{|l|}{ Occupation } \\
\hline Unemployed & 6 & 6.74 \\
\hline Student & 23 & 25.8 \\
\hline Businessman & 5 & 5.62 \\
\hline Service & 10 & 11.24 \\
\hline Housewife & 30 & 33.71 \\
\hline Retired & 6 & 6.74 \\
\hline Others & 9 & 10.11 \\
\hline \multicolumn{3}{|l|}{ Habitat } \\
\hline Urban & 52 & 58.43 \\
\hline Rural & 37 & 41.57 \\
\hline \multicolumn{3}{|l|}{ Marital Status } \\
\hline Married & 58 & 65.17 \\
\hline Unmarried & 30 & 33.71 \\
\hline Divorced & 1 & 1.12 \\
\hline
\end{tabular}

\section{Sources of Referral}

Table-II shows the details of department wise sources of psychiatric referrals. A majority of the referrals were made from the faculty of medicine ( $n=61,68.53 \%)$. The referral rate from Internal Medicine department was the highest $(14.6 \%)$, , followed by Rheumatology (13.5\%), Neurology (10\%) and Nephrology (10\%). Other major sources of psychiatric referrals were the different branches of surgery $(n=13,14.6 \%)$, pediatrics $(n=13$, $14.6 \%)$ and gynecology $(n=2,2.24 \%)$.

\section{Reasons for Referral}

Consultation was sought for various reasons including psychiatric evaluation of referred cases, management of behavioral disturbance, etc. [Table III]

\section{Psychiatric Diagnoses}

The most prevalent DSM-5 diagnosis was Major Depressive Disorder (37.07\%) followed by ObsessiveCompulsive Disorder (17.98\%), Delirium (10.11\%) and others . No psychiatric diagnosis was made in $15.73 \%$ of the referred patients. [Table IV]. 
Table II

Sources of psychiatric referral from different inpatient departments

\begin{tabular}{|c|c|c|c|}
\hline Faculty & Department & Number & Percent \\
\hline \multirow[t]{12}{*}{ Medicine } & Internal Medicine & 13 & 14.6 \\
\hline & Neurology & 9 & 10.1 \\
\hline & Haematology & 1 & 1.1 \\
\hline & Rheumatology & 12 & 13.48 \\
\hline & Nephrology & 9 & 10.1 \\
\hline & Respiratory Medicine & 3 & 3.3 \\
\hline & Cardiology & 3 & 3.3 \\
\hline & Hepatology & 1 & 1.1 \\
\hline & Gastroenterology & 5 & 5.6 \\
\hline & Physical Medicine & 2 & 2.2 \\
\hline & Critical Care Medicine & 2 & 2.2 \\
\hline & Palliative Care Medicine & 1 & 1.1 \\
\hline \multirow[t]{6}{*}{ Surgery } & General Surgery & 2 & 2.2 \\
\hline & Orthopedic Surgery & 1 & 1.1 \\
\hline & Colorectal Surgery & 1 & 1.1 \\
\hline & Neurosurgery & 7 & 7.8 \\
\hline & Vascular Surgery & 1 & 1.1 \\
\hline & Hepatobiliary Surgery & 1 & 1.1 \\
\hline \multirow[t]{5}{*}{ Pediatrics } & General Pediatrics & 4 & 4.4 \\
\hline & Pediatric Neurology & 4 & 4.4 \\
\hline & Pediatric Gastroenterology & 3 & 3.3 \\
\hline & Pediatric Nephrology & 1 & 1.1 \\
\hline & Pediatric Rheumatology & 1 & 1.1 \\
\hline Gynecology & Gynecology & 2 & 2.2 \\
\hline
\end{tabular}

Table-III

Reasons mentioned for requesting consultation

\begin{tabular}{lcc}
\hline Reason for referral & Number & Percent \\
\hline Psychiatric evaluation and management & 85 & 95.5 \\
Management of behavioral disturbance & 3 & 3.37 \\
Management of already diagnosed case & 1 & 1.12 \\
\hline
\end{tabular}

Table IV

Frequency of Psychiatric diagnoses of referred patients

\begin{tabular}{lcc}
\hline Psychiatric Morbidity & Number & Percent \\
\hline Schizophrenia Spectrum Disorder & 3 & 3.37 \\
Bipolar I Disorder & 5 & 5.62 \\
Major Depressive Disorder & 33 & 37.07 \\
Anxiety Disorder & 5 & 5.62 \\
Obsessive-Compulsive Disorder & 16 & 17.98 \\
Conversion Disorder & 6 & 6.74 \\
Somatic Symptom Disorder & 1 & 1.12 \\
Substance Use Disorder & 3 & 3.37 \\
Intellectual Disability & 5 & 5.62 \\
Attention-Deficit/Hyperactivity Disorder & 1 & 1.12 \\
Personality Disorder & 4 & 4.49 \\
Delirium & 9 & 10.11 \\
No Diagnosis & 14 & 15.73 \\
\hline
\end{tabular}

\section{Discussion:}

In the current study, the referred populations were mostly female which is similar to findings from other studies conducted in Bangladesh recently. ${ }^{5,6}$ The age distribution shows most referred cases are between 19-59 years (56\%). Similar finding has been reported by Lipowski et al. ${ }^{7}$ where $70 \%$ of 2000 psychiatric referral were from 20-59 years of age. Educational status of the referred patients was mostly secondary (51.69\%) followed by primary $(22.47 \%)$ and graduate (17.98\%). These figures represent the increased health awareness among literate people. Marital status of our respondents shows $65.17 \%$ married, $33.71 \%$ unmarried and $1.12 \%$ divorced cases. Studies done in Bangladesh ${ }^{5}, \mathrm{Nepal}^{8}$ and America ${ }^{7}$ reports similar results. Urban populations were represented overtly in our study (58.43\%). This may be due to the location of the tertiary hospital in the center of the capital making the service more available to the urban population group. However, the rural population were also represented significantly (41\%). Among the occupations, the housewife comes most frequently (33.71\%). The sociodemographic characteristics of the population indicate that the most likely patients to be 
referred are young and middle-aged female housewives. This pattern may be the reflection of the socio- cultural suppression and somatization of the mental problems of the unemployed females. ${ }^{5}$

In the present study almost two- thirds of the patients have been referred from medicine and allied branches (67.08\%) finding comparable to other studies done in Bangladesh ${ }^{5,9}$ and India. ${ }^{2,4}$ The referral is highest from department of Internal Medicine (14.06\%). The reason behind this may be the peoples' stigma about psychiatric disorder which lead them to somatize their psychological complaints and seeking help to general physicians and internists. Unawareness and lack of information about availability of psychiatric services may also play role. The referral from department of Rheumatology (13.48\%) comes next. It has been widely established that psychiatric disorders especially depression and anxiety are common comorbidity of rheumatological disorders. ${ }^{10}$ The third common source of referral was from department of Neurology (10.1\%) and department of Nephrology (10.1\%). Neurological referral may explain the fact that psychiatric disorders like conversion disorder, somatic symptom disorder; body dysmorphic disorder has a strong resemblance with neurological disorder. Again, many neurological disorders may initially be suspected as psychiatric one like multiple scleroses, stroke, peripheral neuropathy, Parkinson's disease and so on. From this perspective neurological referrals were expected to be higher. Probably neurologists tend to treat the psychiatric cases at first instance which leads to fewer number of referrals. The referrals from Nephrology were mostly for evaluation of kidney transplantation patients (both donor and recipient). The referrals from surgery and allied branches were $14.4 \%$, which is consistent with finding of study done by Avasthi et al (1998). The short stay of surgical patients in hospital and reduced concerns of the surgeons about psychological complaints may be the reason behind this pattern(11). Referral from department of Pediatrics is $14.3 \%$ which matches with the nationwide prevalence of psychiatric disorder in child population is $13.6 \% .^{3}$ Referral from department of Gynecology and Obstetrics is 2.2\% which is far less than expected. Psychiatric morbidities in this group is very high. Apart from postpartum blues, postpartum depression, psychosis and obsessivecompulsive disorders are also very common. A recent study conducted in 376 urban slum sample shows the prevalence of postpartum depression to be $39.4 \% .^{12}$ Given this huge prevalence, it can be assumed that the referral from the respective department is poor. It may reflect the reluctance of the gynecologists' and the obstetricians to refer the patients and tendency to give the initial treatment.
Regarding reasons mentioned for requesting consultation, 95.5\% patients were referred for psychiatric evaluation and management. This figure is comparable to other studies. ${ }^{6,11}$ The reasons behind such pattern may be the poor knowledge about current psychiatric diagnostic and management trends among the physicians and surgeons. This also reflects negligence towards Psychiatry as a full subject in undergraduate curriculum. Management of behavioral disturbance and management of already diagnosed case accounted for $3.37 \%$ and $1.12 \%$ respectively. The cases of behavioral disturbances are later diagnosed as 'Delirium'.

The most common psychiatric diagnosis found in this study was Major Depressive Disorder (MDD) is $37.07 \%$. Depression is a major cause of health burden worldwide affecting approximately 264 million people. ${ }^{13}$ In Bangladesh, it is the most common psychiatric diagnosis affecting $6.7 \%$ population. ${ }^{3}$ The second most common diagnosis is Obsessive- Compulsive Disorder (17.98\%). Two recent studies done in Bangladesh shows the prevalence of OCD $9.06 \% 5$ and $5.66 \%$ (9). The OCD patients don't accept it as disorder and not like to share their symptoms until it is severe and hampering his/her daily life. Many studies did not show the OCD prevalence as a separate entity. The reason behind this may be that the OCD was under the heading of Anxiety Disorders in DSM-IV and the researchers used DSM-IV for psychiatric diagnosis. In our study, we made the diagnoses as per DSM-5 and we carefully interviewed the obsessive- compulsive symptoms. The next common frequency was "No psychiatric diagnosis" (15.73\%). Some Indian studies show similar result. ${ }^{2,14}$ The reason for not receiving any psychiatric diagnosis is that those patients have some psychiatric symptoms which were not sufficient to form any single psychiatric diagnosis. Delirium was diagnosed in $10.11 \%$ cases. The delirious patients frequently show behavioral disturbances which often raise suspicion about psychiatric diagnosis.

\section{Limitation of the study}

There are few limitations of the current study. The sample size of the study was small, as only the patients referred on the day of the authors were taken as sample. It may not be the representative for overall consultation- liaison services. Moreover, the psychiatric diagnoses were assigned by the consultant as per DSM5. If structured interview techniques and standardized rating scales can be used, the reliability and validity of the result were expected to be better.

\section{Conclusion:}

Psychiatric comorbidities in general medical illness are very common. Many physicians focus only on physical 
disorders rather than the holistic approach. Lack of awareness about psychiatric services and fear of stigma often prevents people to seek help from psychiatrists directly. Moreover, primary physicians often do not consider referring the patients to psychiatry department and treat them with psychotropics on their own. This prolongs and, in some cases, may worsen the course of psychiatric illness and negatively impacts the physical illness too. A general medical doctor can play a vital role in addressing such issues. Being a postgraduate university, BSMMU runs many courses including residency program. The placement of psychiatry residents in other departments help the general medical doctors to know about the current trends of psychiatric diagnosis and management. Early recognition of psychiatric morbidity and prompt initiation of treatment may help to reduce patients' sufferings. Thus, CLP provides an opportunity to improve health outcomes for inpatients and reduce burden on the healthcare system.

\section{References}

1. Sadock B, Sadock V, Ruiz P. Kaplan \& Sadock's synopsis of psychiatry. 11th ed. New York: Wolters Kluwer; 2015. p. 499

2. Tekkalaki B, Tripathi A, Arya A, Nischal A. A descriptive study of pattern of psychiatric referrals and effect of psychiatric intervention in consultation-liaison set up in a tertiary care center. Indian $\mathrm{J}$ Soc Psychiatry. 2017;33(2):165. https://doi.org/10.4103/09719962.209181

3. National Institute of Mental Helath. National Mental Health Survey Bangladesh 2019 - Provisional Fact Sheet [Internet]. 2019. p. 4. Available from: https:// www.who.int/docs/default-source/searo/bangladesh/ pdf-reports / cat-2/nimh-fact-sheet-5-1119.pdf?sfvrsn=3e62d4b0_2

4. John S, Thomas S M. Referrals P, Psychiatry L. A study ofpatternofreferralsinliaisonpsychiatry. Indo American journal of pharmaceutical research. 2017;7(10):2-7.

5. Jahan N, Maruf MM, Kauser S, Sarkar M, Sarker MMR, Begum A. Pattern of psychiatric morbidity among referred inpatients in a tertiary care hospital of Bangladesh. Bangladesh J Psychiatry. 2020;31(2):3842. https://doi.org/10.3329/bjpsy.v31i2.45373
6. Fariduzzaman S, Bakar MA, Biswas DM, Mujtaba SM. Consultation-liaison psychiatry in a medical college hospital. Bangladesh Med J Khulna. 2014;46(1-2):213. https://doi.org/10.3329/bmjk.v46i1-2.18235

7. Lipowski Z J, Wolston E J. Liaison psychiatry: Referral patterns and their stability over time. Am J Psychiatry. 1981;138(12):1608-11. https://doi.org/10.1176/ ajp.138.12.1608 PMid:7304795

8. Ranjan S, Poudel R, Pandey P. Pattern of Psychiatric Referral From Emergency Department of a Tertiary Level Hospital in Nepal. J Univers Coll Med Sci. 2016;3(2):59. https://doi.org/10.3126/jucms.v3i2.14283

9. Uddin MJ, Chowdhury MJH, Islam MJ, Chowdhury TI, Baqui M, Sarker PK, et al. Referral Pattern of Patients to Psychiatry Department at Neuroscience Institute in Bangladesh. J Natl Inst Neurosci Bangladesh. 2015;1(1):811. https://doi.org/10.3329/jninb.v1i1.22940

10. Ching Lok EY, Mok CC, Cheng CW, Chi Cheung EF. Prevalence and Determinants of Psychiatric Disorders in Patients With Rheumatoid Arthritis. Psychosomatics. 2010 Jul;51(4):338-338.e8. https://doi.org/10.1016/ S0033-3182(10)70705-2

11. Mullick M S I, Khanam M, Islam H. Referral patterns in outpatients department of Institute of Mental Health and Research.Bangladesh Journal of Psychiatry. 1994 December; 6(2):5-9.

12. Azad R, Fahmi R, Shrestha S, Joshi H, Hasan M, Khan ANS, et al. Prevalence and risk factors of postpartum depression within one year after birth in urban slums of Dhaka, Bangladesh. PLoS One. 2019;14(5). https:/ /doi.org/ 10.1371 /journal.pone.0215735 PMid:31048832 PMCid:PMC6497249

13. James SL, Abate D, Abate KH, Abay SM, Abbafati C, Abbasi N, et al. Global, regional, and national incidence, prevalence, and years lived with disability for 354 diseases and injuries for 195 countries and territories, 1990-2017: a systematic analysis for the Global Burden of Disease Study 2017. Lancet [Internet]. 2018 Nov 10 [cited 2020 May 23];392(10159):1789-858. Available from: https://linkinghub.elsevier.com/retrieve/pii/ S0140673618322797

14. Avasthi A, Sharan P, Kulhara P, Malhotra S, Varma VK. Psychiatricprofilesinmedical-surgicalpopulation: Need for a focused approach to consultation-liaison psychiatry in developing countries. Indian J Psychiat. 1998; 40(3):224-230. 